\title{
Technical Note: In-situ quantification of aerosol sources and sinks over regional geographical scales
}

\author{
G. Buzorius \\ Meteorology department, Naval Postgraduate School, Monterey, USA \\ Received: 27 August 2008 - Published in Atmos. Chem. Phys. Discuss.: 15 January 2009 \\ Revised: 11 June 2009 - Accepted: 18 June 2009 - Published: 22 July 2009
}

\begin{abstract}
In order to obtain the source/sink functions for atmospheric particulates located on the planetary surface or elevated in the atmosphere; direct aerosol emission measurements are required. For this purpose, the performance of an airborne aerosol flux measurement system with an improved 3-kilometer $(\mathrm{km})$ spatial resolution is evaluated in this study. Eddy covariance method was used in flux calculations. A footprint for airborne flux sampling with the increased resolution becomes comparable in area to the footprint for tower sampling (with the footprint length being 2 to $10 \mathrm{~km}$ ). The improvement in spatial resolution allows the quantification of emission rates from individual sources located several kilometers apart such as highway segments, city blocks, and remote and industrial areas. The advantage is a moving platform that allows scanning of aerosol emissions or depositions over regional geographic scales. Airborne flux measurements with the improved spatial resolution were conducted in various environments ranging from clean to partly polluted marine to polluted continental environment with low $(<500 \mathrm{~m})$ mixed boundary layer heights. The upward and downward fluxes from the clean marine environment were smaller than $0.5 \times 10^{6}$ particles $\mathrm{m}^{-2} \mathrm{~s}^{-1}$ in absolute value. The effective emissions measured from a ship plume ranged from $2 \times 10^{8}$ to $3 \times 10^{8} \mathrm{~m}^{-2} \mathrm{~s}^{-1}$, and effective fluxes measured crossing cities plumes with populations of 10000 to 12000 inhabitants were in the range of $2 \times 10^{8}$ to $3 \times 10^{8} \mathrm{~m}^{-2} \mathrm{~s}^{-1}$. Correlations between heat and aerosol fluxes are evaluated.
\end{abstract}

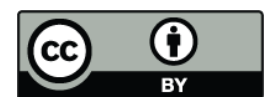

Correspondence to: G. Buzorius (gbuzoriu@nps.edu)

\section{Introduction}

An amount of solar energy reaching planetary surface effectively depends on particles suspended in the atmosphere. Aerosol affects the climate directly by reflecting solar radiation back into space; or indirectly, by forming cloud droplets which are able to reflect solar energy. Additionally, black carbon particles are able to absorb electromagnetic radiation, effectively trapping heat. An overall impact of the atmospheric aerosol has not yet been fully understood. IPCC (2001, 2007) reports pointed out that the largest uncertainties in understanding global anthropogenic climate change are in quantifying the direct and indirect climate effects caused by aerosol.

Recently several field studies (ICARTT, 2004; MACE, 2005; and VOCALS, 2008) were dedicated to parameterize aerosol climate effects. Prior field observations reported changes in cloud properties associated with aerosol sources on the planetary surface. Natural marine aerosol sources changed cloud albedo according to satellite observations reported by Falkoski et al. (1992). Clouds in a continental environment increased their reflectivity after absorbing pollution plumes emitted from urban or industrial environments (Rosenfeld, 2000). One of the challenges in aerosol climatology studies is the determination of the aerosol source function perturbing the cloud. Frequently, the amount of particulates entering cloud is estimated indirectly (for example: by using vertical wind speed variance and aerosol data from flights just below the cloud base) without differentiation between the downdraft and the updraft eddies (Fountakis et al., 2007). More accurate methods differentiate between updraft and downdraft eddies.

Published by Copernicus Publications on behalf of the European Geosciences Union. 
For the quantification of aerosol sources the most direct micro-meteorological tool, the Eddy Correlation (EC) method, was applied in other field experiments. Using the EC method, aerosol emission/deposition parameterizations were derived (for example Nilsson et al., 2001 and Dorsey et al., 2002). In those studies, sampling was conducted from towers and data represented a few square kilometers of the planetary surface area (footprint). Sources that can be quantified with the EC include two major natural aerosol sources: sea spray (Pierce and Adams, 2006) and dust from arid and semi-arid areas, and probably the largest anthropogenic source: traffic. Presently, extrapolation of such data from local scale (waves, eddies and vehicles/roads) to regional or global scales involves considerable uncertainties. This extrapolation is required in order to incorporate the emission/deposition parameterizations into regional climate models.

To derive aerosol emission/deposition parameterizations over an area larger than several square kilometers, a network of measurement towers or sampling from an airplane is required. In a previous study (Buzorius et al., 2006, herein referred to as "the previous paper") aerosol flux measurements from an airplane were reported. Fluxes were derived with a 10-km spatial resolution. Raw data was sampled from an airplane flying at a $50 \mathrm{~m} \mathrm{~s}^{-1}$ velocity. The airborne aerosol flux measurement system allows mapping of aerosol sinks and sources over a distance of hundreds kilometers.

This paper reports improvement of the spatial resolution in measuring airborne aerosol flux by using a $3-\mathrm{km}$ data segment compared to $10-\mathrm{km}$ resolution in the previous study for the covariance estimate. The better resolution allows for more precise mapping of aerosol sources and sinks on the planetary surface. Potentially, the enhanced spatial resolution allows for a direct comparison between the tower and the airborne flux measurement systems since footprints are comparable in size. Use of a tower was not available during this study. Deployment of a mobile platform provides a possibility not only for traditional surface flux studies (such as dry deposition or surface source functions measurements) but also gives a tool for measuring aerosol sinks located at various atmospheric altitudes.

In this study the locally measured aerosol flux data are examined from the perspective of natural physical system behavior, considering possible aerosol ambient sinks and sources located above or below the flown altitude, correlating the aerosol fluxes with heat fluxes, and discussing the physical processes controlling both fluxes. Presented data were sampled in areas with various mixes of natural and polluted air masses ranging from clean marine to polluted continental environments. The effective ship's emission impacts in comparison to the clean marine environment are evaluated. The effective city emissions to the continental environment are quantified.

\section{Experiment setup and site description}

Experimental instrumentation deployed in this study was practically the same as reported in the previous paper but with the replacement of IRGA by LICOR 6262, for measuring water vapor concentration. A brief summary of the setup is presented here.

For fast 3-D wind speed sampling a radome system was deployed in parallel with inertial navigational system (INS) and global positioning system (GPS) (Brown et al., 1983, Tjernsrtom and Friehe, 1991). The random error in measuring wind speed after data post processing is expected to be $0.1 \mathrm{~m} \mathrm{~s}^{-1}$ (Buzorius et al., 2006). For total particle number concentration measurements a modified Condensation Particle Counter (CPC) model TSI 3010 was deployed. During the modification the sample flow rate was increased to $2.35 \mathrm{lpm}$, and the temperature difference between the condenser and saturator was increased to $23^{\circ} \mathrm{C}$. The minimal detectable particle size with $50 \%$ efficiency after the modification was $12 \mathrm{~nm}$ (Buzorius, 2001). The sample inlet was just below the radome. Aerosol was sampled via $1 \mathrm{~m}$ long $4 \mathrm{~mm}$ inner diameter electrically conductive tubing (TSI Inc. part \# 3001788) at $7.5 \mathrm{lpm}$ flow rate to maintain near to turbulent flow regime. Additional instruments were Heitronics KT19.85 infrared thermometer and dew point hygrometer for the sea surface temperature and dew point measurements. Air temperature was measured with a Rosemount platinum resistance thermometer. CPC data were recorded at $10 \mathrm{~Hz}$, all other data at $100 \mathrm{~Hz}$ and during the post processing averaged to $10 \mathrm{~Hz}$. CIRPAS Twin Otter aircraft was used as a measurement platform.

Data in the marine environment were collected during the Adaptive Sampling and Prediction (ASAP) experiment, in August of 2006. The sampling area for this paper was over the Pacific Ocean, off the coast of California, partially overlapping Monterey Bay and shifted north compared to the area reported in the previous paper. Level legs were sampled at approximately $33 \mathrm{~m}$ in elevation. During each flight 8 to 20 vertical atmospheric profiles were taken by airplane ascending/descending from $33 \mathrm{~m}$ to 200 to $600 \mathrm{~m}$ elevation within the study area.

Data from the continental environment were collected during flight over the Salinas Valley, inland from the marine study area on 3 December 2003, flying southeast of Salinas between $-121.4735^{\circ}$ longitude $36.5069^{\circ}$ latitude and $-120.9934^{\circ}$ longitude $36.0614^{\circ}$ latitude in almost a straight line about $66 \mathrm{~km}$ long. Level legs were sampled at approximately $180 \mathrm{~m}$ in elevation as determined by the airplane's radar. West of $-121.1^{\circ}$ longitude the airplane's track was very close to Highway 101. East of the longitude the track shifted south of the highway and was mainly over the agricultural fields and vineyards. The highway in the sample area was surrounded by agricultural fields. 
The Cities of Soledad, Greenfield and King City were along the highway with populations of 11300,12600 and 11000 respectively (US Census, 2000).

\section{Methodology}

\subsection{Eddy-Correlation (EC)}

Aerosol flux $(F)$ was determined through a covariance formula,

$F=\overline{w^{\prime} c^{\prime}}$

the prime denotes a deviation from the mean value and the over bar means an average over the 200 or $60 \mathrm{~s}$ time period. $200 \mathrm{~s}$ and $60 \mathrm{~s}$ long data segments correspond to $10-\mathrm{km}$ and $3-\mathrm{km}$ resolution with averaged airplane speed. $w$ is the vertical wind speed in $\mathrm{m} \mathrm{s}^{-1}, w^{\prime}=w-\bar{w} ; c$ is the aerosol number concentration in $\mathrm{m}^{-3}$ and $c^{\prime}=c-\bar{c}$. The linear de-trending filter was applied to the time series to remove linear trends prior to the calculating fluxes. Fluxes were calculated using the "moving window" at $1 \mathrm{~s}$ increments as described in the previous paper. Positive flux value indicates upward transport.

It is assumed that turbulence field is constant during 200 or $60 \mathrm{~s}$ time period. This "frozen turbulence" hypothesis is more challenged for tower sampling where the minimum time period used in the covariance formula frequently is $30 \mathrm{~min}$ (Pryor et al., 2007). Analysis of uncertainties in flux estimate associated with the turbulence field dynamics is poorly addressed in scientific literature. Selection of the comparably shorter (60 s versus $200 \mathrm{~s}$ or $30 \mathrm{~min}$ ) time periods significantly reduced the uncertainties associated with the hypothesis.

The flux uncertainties were due to the error in measuring vertical wind speed, limited counting statistics, and limited CPC response time. Each of the first two random errors were approximately $0.2 \times 10^{6}$ particles $\mathrm{m}^{-2} \mathrm{~s}^{-1}$ when the aerosol number concentration was about $10^{3}$ particles $\mathrm{cm}^{-3}$ (Buzorius et al., 2006). The increase of the spatial resolution from $10-\mathrm{km}$ to $3-\mathrm{km}$ segment caused an increase of random errors by a factor of $\sqrt{\frac{200}{60}} \approx 1.8$. Both random errors can be reduced by increasing the time window in the flux formula, or by repeating measurements in the same sampling area under the similar environmental conditions. The systematic error due to the CPC limited response was minimized by the "speedup" method (Buzorius et al., 2006). A more detailed discussion of the measurement errors was reported in the previous paper. The "Webb correction" is presented further in this paper.

\subsection{Footprint}

The planetary surface area contributing to the flux sampled at the specific location is defined as a footprint for that location. There is a distance from the sampling inlet towards the upwind direction within the footprint, at which the contribution peaks and decays faster towards the sampling tower and comparably slower towards the upwind direction. The peak is sharper and the footprint area is smaller during the unstable atmospheric conditions and over the rough surfaces. Leclerc and Thurstell (1990) estimated that 90\% of the flux is caused by processes at the surface area extending 0.1 to $8 \mathrm{~km}$ from the tower towards the upwind direction, when the sampling altitude is $30 \mathrm{~m}$ during the neutral stratification and the roughness length being 6 millimeters $(\mathrm{mm})$. For a roughness length of $0.6 \mathrm{~mm}$ (in the marine case study, the roughness length was found to be from 0.1 to $2.5 \mathrm{~mm}$ ) the peak distance is about $800 \mathrm{~m}$. Other footprint models for similar environmental conditions suggested a peak distance of 1 to $2 \mathrm{~km}$ and a $90 \%$ flux distance of 3 to $6 \mathrm{~km}$ (http://footprint.kljun.net/contact.php). During test flight above the land $90 \%$ of flux was contributed from $10 \mathrm{~km}$ long fetch. The terrain was relatively non-homogenous varying from highway to urban to agricultural fields and vineyards; and asymmetric footprints were probable (Vesala et al., 2007). Overview of footprint modeling for fixed location sampling was presented by Vesala et al. (2008).

The footprint for airborne sampling is going to be somewhat skewed along the airplane track. It has a different shape for airplanes flying along the wind direction and in perpendicular alignment. Yet, a more detailed study on the footprint, while sampling from an aircraft, is out of the scope of this paper.

\subsection{Webb correction}

Webb et al. (1980) pointed out that measured concentration fluxes of the atmospheric constituent can be affected by heat or water vapor fluxes. The reasoning was that for the heat flux being directed upwards, an air parcel rising towards the sampling point has a slightly higher temperature and therefore, a slightly lower air density compared to the descending air parcel. The similar effect occurs due to the water vapor flux since partial vapor pressure is a component in the air parcel total pressure. The particle flux components due to the sensible or latent heat fluxes are proportional to the sensible or latent heat fluxes and aerosol concentration. Total particle flux, as shown below in Eq. (2), is:

$F=\overline{w^{\prime} c^{\prime}}+1.61 \frac{\bar{c}}{\rho_{a}} \overline{w^{\prime} \rho_{v}}+(1+1.61 \bar{q}) \frac{\overline{w^{\prime} T^{\prime}}}{\bar{T}} \bar{c}$

where $T$ is the absolute temperature; $\rho_{a}$ is the density of dry air; $\rho_{v}$ is the density of water vapor; and $q$ with overbar is the averaged specific humidity. Both corrections are significant when the covariance of aerosol and vertical wind speed is low and the sensible and latent heat fluxes are high. 


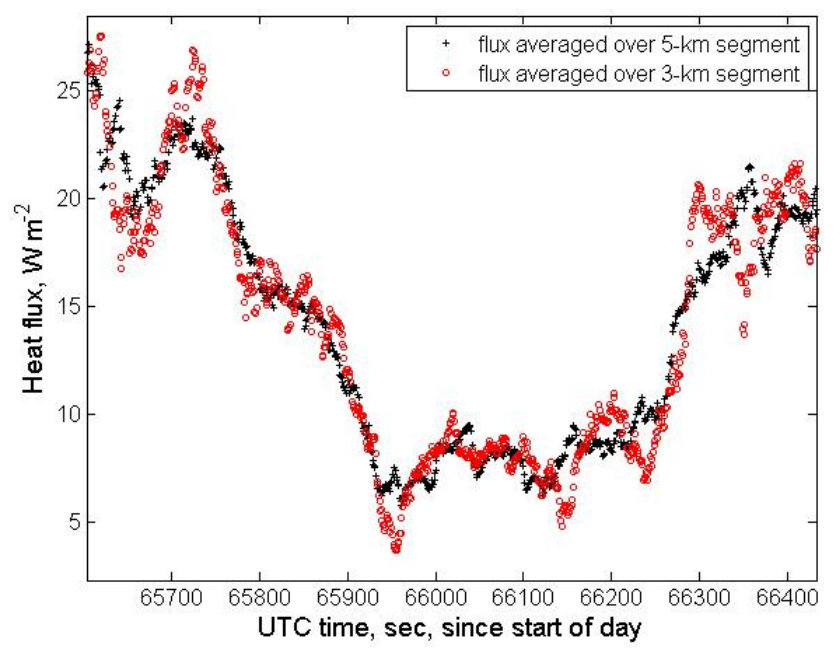

Fig. 1. Heat flux sampled at $33 \mathrm{~m}$ elevation above the ocean over a distance of about $40 \mathrm{~km}$.

\subsection{Spatial resolution}

In order for the covariance estimate (Eqs. 1 and 2) to be representative of the vertical flux, a sampling of the full size range of atmospheric eddies is required. The range defines the length of time series (in the time space for tower measurements and the distance space for airborne studies) of two atmospheric scalars that are required in the covariance formula. Typically, the length is defined using a cumulative sum (Ogive) or co-spectrum analysis.

A comparison reported in the previous paper (Fig. 6, Buzorius et al., 2006) between the airborne heat flux calculated for every 5-km segment and the heat flux derived using the bulk method (COARE 3.0) showed a general agreement. It was concluded in the previous paper that $5-\mathrm{km}$ segments were long enough to capture the full range of eddy sizes.

Figure 1 shows a comparison between heat fluxes derived using EC over 5-km and 3-km segments. The data were collected in the marine environment during an 8 August 2006 flight. The variability in the heat flux was caused by a drop in the sea surface temperature due to the cold water upwelling in coastal waters. The fragment of the flight is presented where the airplane flew in and out of the area with the lower Sea Surface Temperature (SST). The 3-km segment heat flux shows the slightly steeper changes compared to the $5-\mathrm{km}$ segment fluxes, because the later uses longer averages. Overall, both flux series tracked well the changes in the heat flux. As shown in the previous paper, with the $5-\mathrm{km}$ segment fluxes resembling values of the bulk estimates, and the $3-\mathrm{km}$ segment fluxes having very similar values compared to the $5-\mathrm{km}$ segment fluxes, it can be safely assumed that the $3-\mathrm{km}$ segments have sufficiently long series to capture the full range of the eddy size spectrum. Since the heat flux is primarily driven by heat exchange between the sea surface and the at- mosphere, it is safe to assume that a flux of another atmospheric constituent (for example, aerosol concentration), that is primarily driven by material exchange across the oceanatmosphere interface, will be sufficiently represented by a 3-km segment covariance.

Aerosol concentration power spectrum from "FastFourier-Transformation" or "Ogive" analyses are more direct methods in verifying the minimum length of the data stream required in the covariance equation. FFT analysis was performed for every straight leg flown during the experiment (not presented). Aerosol concentration in the coastal environment was frequently increased tenfold by human-caused sources. If a 3-km segment was of the clean marine aerosol with total number below 1.000 particles $\mathrm{cm}^{-3}$, extending that segment to 5 - or $10-\mathrm{km}$, frequently lead to the incorporation of anthropogenic aerosol plumes from ships or continental polluted air encountered by the airplane further into the flight. The Ogive (spectrum) analysis was frequently corrupted by such plumes.

Mixed Boundary Layer (MBL) height defines the dominant atmospheric eddy sizes. In this paper, it was adopted that the segment length used in Eqs. (1) and (2) has to be several times longer than the MBL height (see also Businger, 1986). Below, the results will be presented from comparisons between the $3-\mathrm{km}$ and the $10-\mathrm{km}$ segment aerosol fluxes sampled in various environments.

\section{Results and discussion}

Calculated aerosol fluxes included all of the abovementioned corrections. The Webb correction in the marine environment was less than $3 \%$ in $70 \%$ flux data points and was less than $5 \%$ in $80 \%$ of data. In the continental environment the correction was less than $2 \%$.

Presented here are locally (approximately at $33 \mathrm{~m}$ elevation) measured fluxes. Direct comparison between the local flux and the surface flux is impossible because the later was not available. Theoretically, the total aerosol number flux divergence between the surface and the measurement elevation occurs due to coagulation, the process that over a time reduces total aerosol number concentration. However, if the coagulation occurs with the same rate in updraft and downdraft air parcels, then the EC value is not affected by the coagulation. Additionally, coagulation is negligible in clean marine environment with low wind speeds over a time period comparable to characteristic atmospheric time scales. The main interest in this study is the experimental determination of aerosol local flux in various environments. Examples below illustrate situations when local fluxes are dominated by exchange across planetary surface-atmosphere interface or by dilution with atmospheric layers aloft. 


\subsection{Aerosol fluxes in a clean marine environment}

In a clean marine environment, local fluxes measured at approximately $33 \mathrm{~m}$ altitude represent an overall sum of forces causing upward and downward directed aerosol transports. Forces are caused mainly by the aerosol generation and removal processes, acting independently of each other. The aerosol generation is caused by bubble bursting during breaking waves. Atmospheric turbulence carries particles from the ocean-atmosphere interface to higher elevations and mixes them through the entire mixed boundary layer column with typical height being from 100 to $500 \mathrm{~m}$. Aerosols are removed from the MBL by precipitation scavenging, dry deposition (Slinn and Slinn, 1980), entrainment aloft of the mixed boundary layer, coagulation (reduces the number, not the mass) and some particles can be activated into cloud droplets.

Measured aerosol number concentration varied from 300 to 800 particles $\mathrm{cm}^{-3}$. Similar values were reported in other sites from clean marine environment (Bates et al., 2000). Vertical soundings sampled during spirals indicated a homogeneous mix of aerosol number in MBL in clean marine environment for most of the flights in offshore locations. Measured aerosol fluxes in the clean marine environment on average were consistently within the range $-0.5 \times 10^{6}$ to $+0.5 \times 10^{6}$ particles $\mathrm{m}^{-2} \mathrm{~s}^{-1}$. During most of the flights conducted in ASAP experiment the horizontal wind speed was un-characteristically low (less than $8 \mathrm{~m} \mathrm{~s}^{-1}$ at nominal $10 \mathrm{~m}$ elevation). Detected upward fluxes ranged similarly compared with the data from other sites (Nilsson et al., 2001; O'Dowd and de Leeuw, 2007). For example, the Arctic Ocean sea spray flux measurements reported upward flux of $0.62 \times 10^{6} \mathrm{~m}^{-2} \mathrm{~s}^{-1}$ during $8 \mathrm{~m} \mathrm{~s}^{-1}$ horizontal wind at the nominal height.

Experimental data from various field campaigns suggested a factor of 2 in the variability of the sea spray source strength for the given wind speed (Clarke et al., 2006). Water temperature was identified as one of the variables modifying the function (Mårtensson et al., 2003), while other factors are still subject of research (Lewis and Schwartz, 2004). Recently, dissolved organic materials were identified as a possible primary marine aerosol source (Tyree et al., 2007; O'Dowd and DeLeeuw, 2007; Nilsson et al., 2007). Using an airplane as a measurement platform it was possible to measure the aerosol flux over two marine areas that are different only by one physical or chemical property but otherwise are identical. Within the sampling area during the AOSN (the previous study) and ASAP experiments ocean surface pools with the increased chlorophyll concentrations were observed using a remote sensing spectroscopic instrument installed on the airplane (not presented here). Unfortunately, data analysis showed significant ship emissions in areas with the chlorophyll pools during AOSN field campaign and unusually low wind speeds (minimal white cap areas) during the ASAP experiment in 2006. Due to these reasons this dataset was not suitable for detecting the upward natural

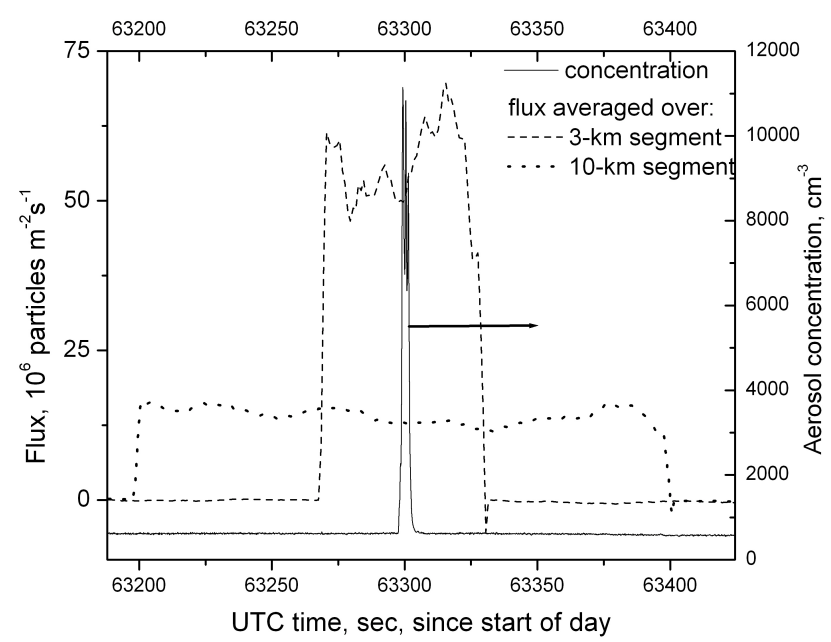

Fig. 2. A sharp rise in aerosol concentration and aerosol fluxes due to ship emissions sampled on 12 August 2006.

marine aerosol flux enhancement over the chlorophyll pools. The flux increase is expected if there was a primary source of organic carbon aerosol that was not internally mixed with $\mathrm{NaCl}$.

\subsection{Single plume in a clean environment}

In the sampling area the marine aerosol was superimposed with particles emitted from ships. Figure 2 presents an example of the $10-\mathrm{km}$ and the $3-\mathrm{km}$ segment aerosol fluxes while the airplane crossed a pollution plume from a ship on the 12 August 2006 flight. Particle concentration plotted on the right-y axis shows an increase from 500 particles $\mathrm{cm}^{-3}$ outside the plume to 11000 particles $\mathrm{cm}^{-3}$ inside the plume. The width of the spike at the half height was $3 \mathrm{~s}(150 \mathrm{~m})$. On that day measured wind speeds were 1 to $3 \mathrm{~m} \mathrm{~s}^{-1}$ at a $33 \mathrm{~m}$ elevation. The very calm weather lead to the relatively slow dispersion of the plume. Almost a delta-function behavior in the concentration time series provided a good example for demonstrating the differences between the $10-\mathrm{km}$ and the 3$\mathrm{km}$ segment fluxes (dotted and dashed lines).

EC method requires a horizontal homogeneity in scalar concentration. The requirement is not satisfied after the plume levels-off and causes spatial non-homogeneity in aerosol concentration. In non-homogeneous environment the direction of EC flux fluctuates significantly because an increase in aerosol number from the mean value coincides randomly with the vertical wind speed direction and the fluxes have the relatively large absolute values. In the presented example it is assumed that the airplane encountered a plume in the relatively early stage, before the leveling-off. The assumption is supported by the short cross-sectional plume distance that indicated of the relatively short horizontal distance from the ship, and consistently upward fluxes. 


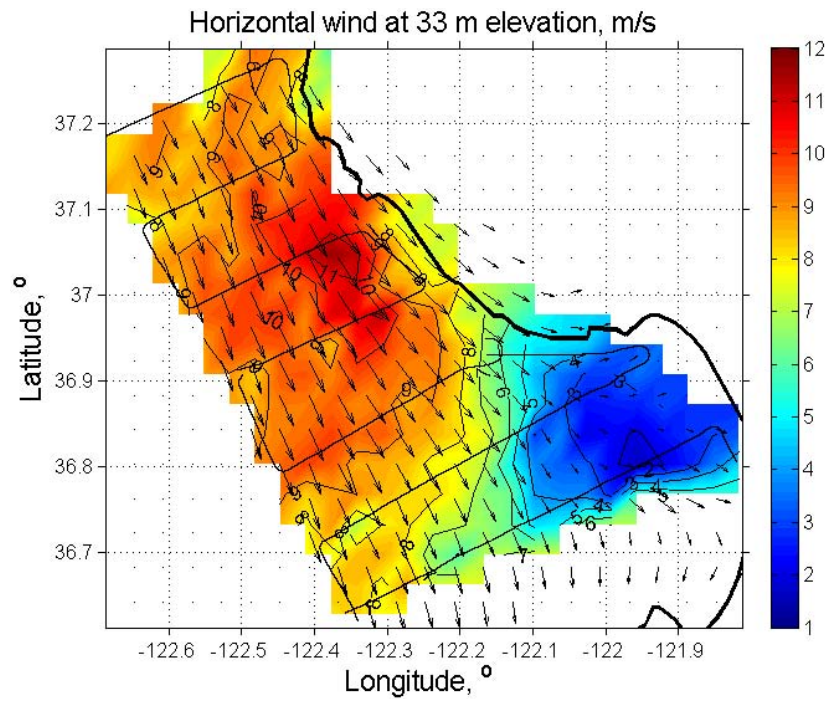

Fig. 3. Wind speed and direction distribution on 8 August 2006. Thin line indicates airplane track, thick line shows coastline.

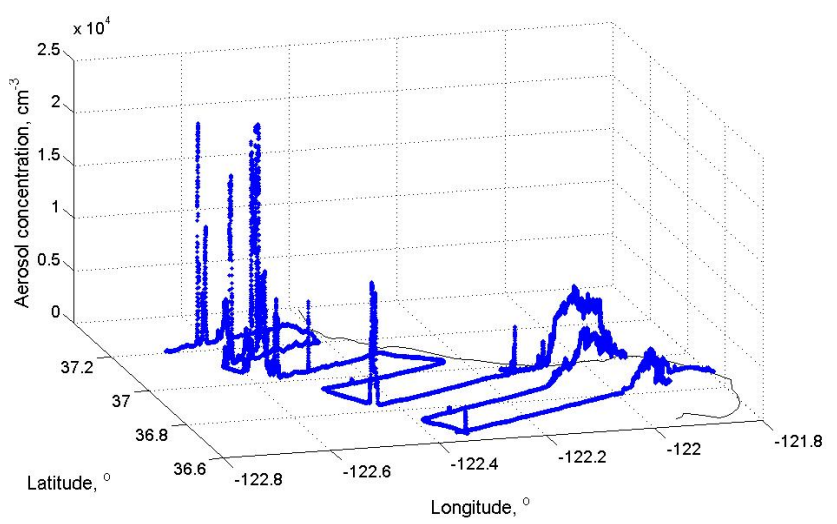

Fig. 4. Spatial distribution of total aerosol number concentration.

The fluxes outside the plume were smaller than $10^{6}$ particles $\mathrm{m}^{-2} \mathrm{~s}^{-1}$. When the plume was encountered, the $10-\mathrm{km}$ segment flux increased to about $15 \times 10^{6}$ particles $\mathrm{m}^{-2} \mathrm{~s}^{-1}$ and the $3-\mathrm{km}$ segment flux jumped to a range of $50 \times 10^{6}$ to $70 \times 10^{6}$ particles $\mathrm{m}^{-2} \mathrm{~s}^{-1}$. An integral area under the flux curve (not the curve maximal values) represents the effective source strength. The integral area under the $3-\mathrm{km}$ flux curve is about $15 \%$ larger compared to the area under the 10-km flux curve.

\subsection{Multiple plumes}

On the 8 August 2006 flight, a total four large ships were present in the sampling area. This flight provided an example of the overlap of several plumes in a clean marine environment. One of the ships, a Hyundai containership, was visually observed several times from the airplane, while

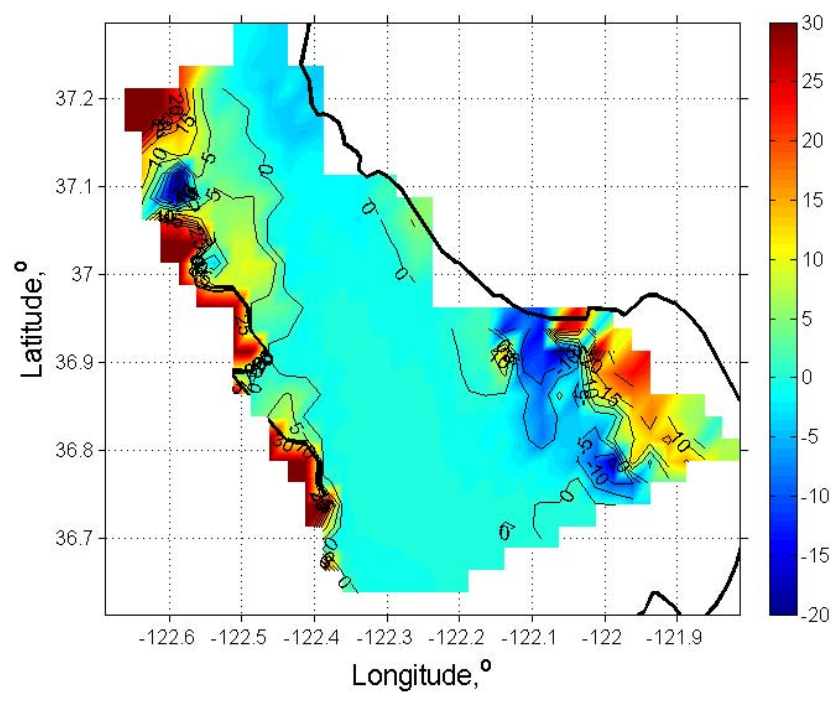

Fig. 5. Aerosol flux calculated over each $10-\mathrm{km}$ segment sampled 8 August 2006. Thick line is coastline. Color scale is units of particles $10^{6} \mathrm{~m}^{-2} \mathrm{~s}^{-1}$.

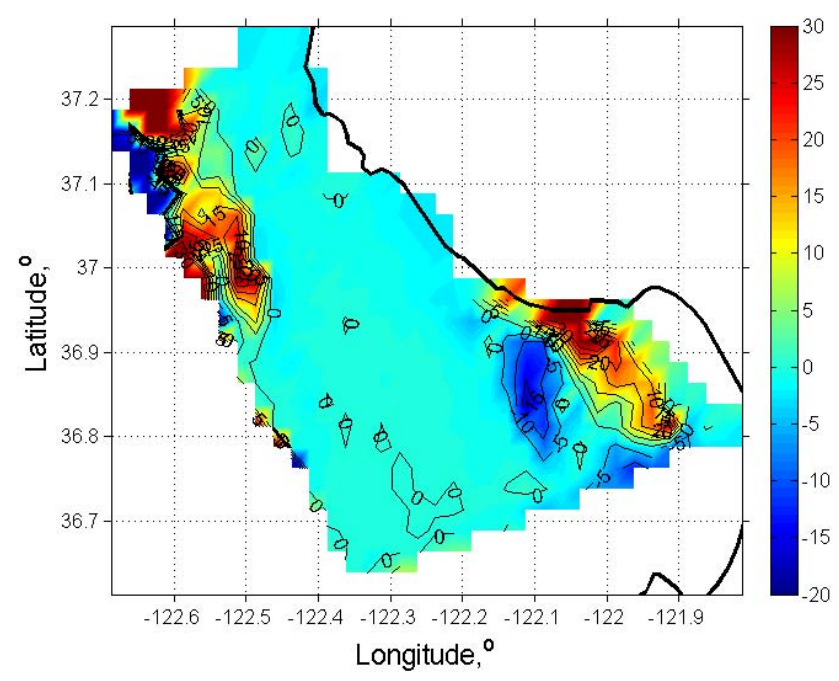

Fig. 6. Same as Fig. 5 but aerosol flux was calculated over each 3-km segment.

the other three were detected by the airplane's radar. During the flight fragment that was the closest to the shoreline, a continental aerosol was mixed with the marine aerosol. Figure 3 demonstrates the wind patterns on that day. Averages over $0.035 \times 0.035$ degrees of longitude and latitude cells were used in the contour plot. The color of each cell resulted from the bilinear interpolation of the color of its four vortices (the later applies to Figs. 5 and 6 as well). Wind direction was from the northwest, which is typical for the area. Wind speeds varied from 8 to $10 \mathrm{~m} \mathrm{~s}^{-1}$ outside the bay, and subsided to less than $4 \mathrm{~m} \mathrm{~s}^{-1}$ inside the bay due to air flow expansion downwind of the cape. Virtual potential tem- 
perature vertical soundings showed a homogeneous mix between the surface and 300 to $400 \mathrm{~m}$ in elevation at offshore locations. The sounding sampled close to the shoreline inside the bay showed a decoupling at $220 \mathrm{~m}$ in altitude where the temperature increased, due to outflow aloft of the warmer continental air. Fig. 4 illustrates aerosol number concentrations measured at $33 \mathrm{~m}$ elevation during that flight. In areas with clean marine air masses aerosol number concentrations varied from 300 to 800 particles $\mathrm{cm}^{-3}$. In the ship's plume aerosol number increased to $10^{4}$ to $2 \times 10^{4}$ particles $\mathrm{cm}^{-3}$. The single spike at about $-122.45^{\circ}$ longitude and $36.8^{\circ}$ latitude was from the Hyundai containership when it was visually observed from the airplane for the first time. Multiply spikes at $-122.6^{\circ}$ longitude and 36.9 to $37.2^{\circ}$ latitude were from several plumes. Approaching the coastline, the continental pollution increased the aerosol number concentration to about 9000 particles $\mathrm{cm}^{-3}$.

In Figs. 5 and 6 aerosol fluxes were calculated using the $10-\mathrm{km}$ and the $3-\mathrm{km}$ segments. Differences between the figures demonstrate the improved spatial resolution. For example, a small area in red marks the single concentration spike at $-122.45^{\circ}$ longitude and $36.8^{\circ}$ latitude (Fig. 6). While Fig. 5 shows strong upward fluxes in the unrealistically larger area compared to the corresponding spike in concentration data from Fig. 4. Multiple plumes in the northern part mainly caused strong upward fluxes. Strong downward fluxes (see blue patches close to plumes) adjacent to the upward fluxes in the plume were also observed. Those were caused by the plume aerosol deposition to the ocean surface and random errors in measuring turbulence (Rannik and Vesala, 1999) or errors due to non-homogeneity in aerosol concentration. Figure 6 presents more precise locations than Fig. 5 of the emission sources referenced to the spikes in concentration data from Fig. 4. Aerosol flux maximal values in ship plumes were reaching $3 \times 10^{8} \mathrm{~m}^{-2} \mathrm{~s}^{-1}$. The range of color scale in both figures was reduced for a visually better representation of the variability in flux direction (dark red marks fluxes larger than $30 \times 10^{6} \mathrm{~m}^{-2} \mathrm{~s}^{-1}$ ). Additional reduction in the flux amplitude in Figs. 5 and 6 was due to spatial averaging across $0.025 \times 0.025$ degrees of longitude and latitude cells.

Inside the bay a pollution plume from the City of Santa Cruz was observed. The plume increased total aerosol number concentration to $\sim 9000$ particles $\mathrm{cm}^{-3}$. Upward fluxes were caused by the aerosol dilution aloft of the measurement altitude, where a drop in aerosol concentration was observed from vertical profile data (not pictured). On the western side of the plume, downward fluxes were observed. The sea surface was acting as a net aerosol sink due to the dry deposition of plume particles (Slinn and Slinn, 1980; Sievering, 1981). The relatively high aerosol number in the continental plume yielded to strong downward fluxes $\left(-10^{7}\right.$ to $-15 \times 10^{6} \mathrm{~m}^{-2} \mathrm{~s}^{-1}$ ). This behavior (upward flux in the continental plume and the downward flux from the west side) was observed during other flights as well, when winds brought continental pollution to the marine environment.

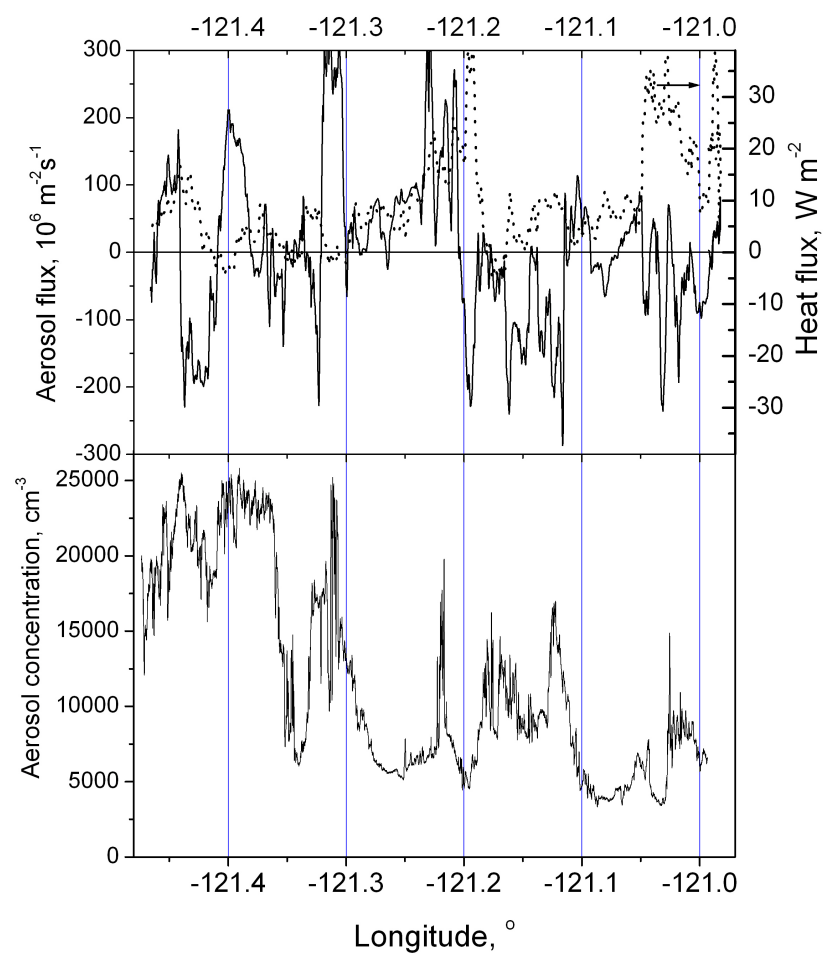

Fig. 7. Aerosol sampling across $66 \mathrm{~km}$ distance $180 \mathrm{~m}$ above the land. Bottom panel shows total aerosol number concentration $(10 \mathrm{~Hz})$. Top panel shows 3-km aerosol flux on the left-y axis. Heat flux is in dotted line (right-y axis).

Effective flux measured from transect of a single ship plume was as high as $3 \times 10^{8}$ particles $\mathrm{m}^{-2} \mathrm{~s}^{-1}$. A fraction of the emitted particles with dominant sizes in the Aitken mode are able to act as cloud condensation nuclei (CCN). Ship emissions mixed into marine clouds are able to reduce the cloud droplet effective radius and to increase the cloud albedo (Hobbs et al., 2000). Exact parameterizations linking the aerosol source strength and the change in the albedo are very scarce in scientific literature, partly due to the lack of flux measurements. Direct measurements of $\mathrm{CCN}$ flux are not available because CCN counters do not satisfy EC requirements. When other significant aerosol sink/sources are not present, the CCN flux can be preliminary estimated indirectly by determining a fraction of $\mathrm{CCN}$ within the total aerosol number concentration and projecting that fraction to the total aerosol number flux.

\subsection{Polluted environment}

Figure 7 presents the aerosol concentration in the bottom panel, the aerosol and the heat fluxes in the corresponding top panel left-y and right-y axes, sampled above the land. The plot presents data collected over the 66-km long study area. At longitudes $-121.4^{\circ},-121.31^{\circ},-121.195^{\circ}$ and $-121.04^{\circ}$ to $-121.02^{\circ}$ the aerosol (solid line) and the heat 
fluxes (dotted line) were negatively correlated. At $-121.4^{\circ}$ and $-121.31^{\circ}$ longitude, the positive aerosol flux concurred with a very high $\sim 25000 \mathrm{~cm}^{-3}$ aerosol number and the downward heat flux. An upward heat flux was expected over the land on sunny day. However, here a small $(\sim-2$ to $-5 \mathrm{~W} \mathrm{~m}^{-2}$ ) but downward heat flux was observed. Most likely, the air masses at $180 \mathrm{~m}$ elevation west of $-121.3^{\circ}$ longitude did not represent properties of the air masses close to the planetary surface. The plotted data suggests the mixing between the polluted air from the valley and the warmer air from aloft. The warmer layer aloft was noticed examining vertical soundings data: at $470 \mathrm{~m}$ elevation virtual potential temperature jumped to $294 \mathrm{~K}$ from $292 \mathrm{~K}$. Atmospheric layer between $180 \mathrm{~m}$ and $470 \mathrm{~m}$ elevations had a stable 292 $\mathrm{K}$ virtual potential temperature. Simultaneously, the aerosol number concentration was reduced by about $50 \%$ above the $470 \mathrm{~m}$ elevation. The mixing of such air masses resulted in the strong upward aerosol and the downward heat fluxes. In these episodes the upward aerosol flux was due to aerosol dilution aloft of the measurement elevation.

At longitudes $-121.195^{\circ}$ and $-121.04^{\circ}$ to $-121.02^{\circ}$ the aerosol concentration decreased to 3.000 to 5.000 particles $\mathrm{cm}^{-3}$, typical values for a remote continental environment. Simultaneously, the heat flux increased to 30 to $40 \mathrm{~W} \mathrm{~m}^{-2}$ range and the aerosol flux was downwards fluctuating between 0 to $-200 \times 10^{6}$ particles $\mathrm{m}^{-2} \mathrm{~s}^{-1}$. The relatively low aerosol number concurrent with the increase in the upward heat flux and the downward aerosol flux were characteristics of the air mass coming from low elevations, close to the planetary surface. The upward heat flux was caused by the heat transfer from the planetary surface warmed-up by the solar radiation. The downward aerosol flux was caused by the surface acting as an aerosol sink via the dry deposition mechanism (Lamaud et al., 1994, Slinn, 1982, Pryor et al., 2007). The heat and aerosol transfer across the interface between the planetary surface and the atmosphere explains the observations for the given longitude segments.

Numerous anthropogenic aerosol sources such as highway and local traffic (Dorsey et al., 2001, Mårtensson et al., 2006), agricultural activities, and advection caused variability in aerosol concentration time series. Pollution plumes were overlapped, and tracing each of them to the specific source was impossible for all but a couple major plumes.

Using the wind direction data and Google Earth mapping techniques, the aerosol concentration increases at $-121.31^{\circ}$ and $-121.22^{\circ}$ longitude in Fig. 7 bottom panel were attributed to emissions from Soledad and Greenfield with the corresponding upward aerosol fluxes in top panel. Similar measurements from the City of Stockholm, Sweden (population 750000) showed fluxes (Mårtensson et al., 2006) reaching a $\sim 2 \times 10^{9}$ to $3 \times 10^{9}$ particles $\mathrm{m}^{-2} \mathrm{~s}^{-1}$ range, while in this study urban fluxes were as high as $\sim 3 \times 10^{8}$ particles $\mathrm{m}^{-2} \mathrm{~s}^{-1}$. The emissions were driven by traffic and comparably the smaller traffic intensity from the smaller cities lead to the lower emission rates. Note that the aerosol concentration in the Soledad and Greenfield plumes and the Stockholm tower measurements are in the same range reaching 25000 particles $\mathrm{cm}^{-3}$ (the upper limit for identical instruments used in both projects), yet the fluxes differ by an order of magnitude.

\section{Conclusions and Summary}

This work reports airborne aerosol flux measurements with an improved spatial resolution to $3-\mathrm{km}$ segments. The $3-\mathrm{km}$ distance is similar to a footprint length when fluxes are sampled from towers at the same $33 \mathrm{~m}$ elevation. The increase in the spatial resolution from $10-\mathrm{km}$ to $3-\mathrm{km}$ allows for more precise source localizations, which becomes valuable when several sources are present. This study increases the variety of scientific applications of eddy correlation method for estimating aerosol sources and sinks. The presented method is particularly useful when the effective fluxes have to be measured during the relatively short time period to assure the same meteorological conditions over a wide distance: estimating aerosol source strengths for various city grids, industrial areas, ocean surfaces varying by one parameter while other (for example horizontal wind speed, water temperature) are identical. An alternative is deployment of EC towers network that is not necessarily cost affective and sometimes impossible.

The presented measurements were conducted under ambient conditions where the $3-\mathrm{km}$ horizontal segment is several times longer compared to the mixed boundary layer height. The measured local aerosol emission rates from the clean marine environment were smaller than $0.5 \times 10^{6} \mathrm{~m}^{-2} \mathrm{~s}^{-1}$ during the relatively low horizontal wind speeds conditions. Positive values of the measured natural marine aerosol flux were similar to those reported in other sites. The effective emissions from ship plumes and cities (populations of 10000-12000) were in the range of a $2 \times 10^{8}$ to $3 \times 10^{8}$ particles $\mathrm{m}^{-2} \mathrm{~s}^{-1}$. The ocean surface acted as a sink for marine and continental aerosols with removal rate of $-0.5 \times 10^{6} \mathrm{~m}^{-2} \mathrm{~s}^{-1}$ and $-10^{7} \mathrm{~m}^{-2} \mathrm{~s}^{-1}$ to $-15 \times 10^{6} \mathrm{~m}^{-2} \mathrm{~s}^{-1}$, respectively. The flux correction due to the air density fluctuations were smaller than $2 \%$ in the continental environment, and smaller than $5 \%$ in $80 \%$ data points in the marine environment. A high scientific interest of this dataset was to compare the natural marine aerosol emission flux from the ocean surface area with the chlorophyll pool to the flux outside the pool, while all other environmental parameters are identical. However, low wind speeds (less than $8 \mathrm{~m} \mathrm{~s}^{-1}$ at $33 \mathrm{~m}$ elevation for the majority of flights) during ASAP field campaign significantly limited white cape areas (no breaking waves), and reduced the release of particulates from the ocean to the atmosphere via the bubble burst mechanism. No significant difference in the fluxes between areas was observed. 
Aerosol flux from urban areas primarily was upwards with traffic being one of the main particle sources. Outside the urban plume, aerosol fluxes were found to be downwards or upward: when the planetary surface was acting as a net aerosol sink; or the fluxes resulted from mixing with the relatively cleaner air masses aloft. A vertical aerosol concentration profile and/or a reference to the heat flux direction was required in interpreting the aerosol local flux data collected from the single altitude.

The technique provides a unique tool for aerosol source and sink quantifications over regional geographical scales with a spatial resolution of $3-\mathrm{km}$. Additionally the technique is suitable for measurement of aerosol transport to layers aloft - a useful tool in cloud-aerosol interaction studies. Such data can significantly contribute to parameterizations of aerosol climatic effects and in regional climate models. Further research is required for the better understanding of the link between the local and surface fluxes, aerosol flux divergence, and footprint for airborne sampling.

Acknowledgements. This study was supported by NSF SGER grant \# 0634147. Author is thankful to S. Ramp from Naval Postgraduate School (NPS) for accommodating aerosol flux study during the ASAP field campaign. Q. Wang (NPS) and J. Kalogiros (NPS) are acknowledged for sharing post-processed wind speed data. Author is grateful to $\mathrm{N}$. Kljun for footprint estimates provided at website http://footprint.kljun.net/contact.php.

Edited by: M. Kulmala

\section{References}

Bates, T. S., Quinn, P. K., Covert, D. S., Coffman, D. J., Johnson, J. E. and Wiedensohler, A.: Aerosol physical properties and processes in the lower boundary layer: a comparison of shipboard sub-micron data from ACE-1 and ACE-2, Tellus, 52B, 258-272, 2000.

Brown, E. N., Friehe, C. A., and Lenschow, D. H.: The use of pressure fluctuations on the nose of an aircraft for measuring air motion, J. Clim. Appl. Meteorol., 22, 171-180, 1983.

Businger, J. A.: Evaluation of the accuracy with which dry deposition can be measured with current micrometeorological techniques, J. Clim. Appl. Meteorol., 25, 1100-1124, 1986.

Buzorius, G., Kalogiros, J., and Varutbangkul, T.: Airborne aerosol flux measurements with eddy correlation above the ocean in coastal environment, J. Aerosol Sci., 37, 1267-1286, 2006.

Buzorius, G.: Cut-off sizes and time constants of the CPC TSI 3010 operating at 1 to $3 \mathrm{lpm}$ flow rates, Aerosol Science and Technology, 35, 577-585, 2001.

Clarke, A. D., Owens, S. R., and Zhou, J., An ultrafine sea-salt flux from breaking waves: Implications for cloud condensation nuclei in remote marine atmosphere, J. Geophys. Res., 111, D06202, doi:10.1029/2005JD006565, 2006.

Dorsey, J. R., Nemitz, E., Gallagher, M. W., Fowler, D., Williams, P. I., Bower, K. N. and Beswick, K. M., Direct measurements and parameterization of aerosol flux, concentration and emission velocity above a city, Atmos. Environ., 36, 791-800, 2002.
IPCC: Climate Change 2001, Intergovernmental Panel on Climate Change, edited by: Houghton, J. T. and Ding, Y., published by Cambridge University press, 2001.

IPCC: Climate Change 2007, Intergovernmental Panel on Climate Change, http://www.ipcc.ch, 2007.

Hobbs, P. V., Garrett, T. J., Ferek, R. J., Strader, Sc. R., Hegg, D. A., Frick, G. M., Hoppel, G. M., Gasparovic, R. F., Russell, R. F., Johnson, L. M., O’Dowd, C. D., Durkee, C., Nielsen, P. A., and Innis, K. E.: Emissions from ships with respect to their effects on clouds, J. Geophys. Res., 57, 2570-2590, 2000.

Falkowski, P. G., Kim, Y., Kolber, Z., Wilson, S., Wirick, C., and Cess, R.: Natural versus anthropogenic factors affecting lowlevel cloud albedo over the North Atlantic, Science, 256, 13111313, doi:10.1126/science.256.5061.1311, 1992.

Fountoukis, C., Nenes, A., Meskhidze, N., Bahreini, R., Conant, W. C., Jonsson, H., Murphy, S., Sorooshian, A., Varutbangkul, V., Brechtel, F., Flagan, R. C. and Seinfeld, J. H., Aerosol-cloud drop concentration closure for clouds sampled during the International Consortium for Atmospheric Research on Transport and Transformation 2004 campaign, J. Geophys. Res., 112, D10S30, doi:10.1029/2006JD007272, 2007.

Lamaud, E., Chapuis, A., Fontan, J., Serie, E.: Measurements and parameterization of aerosol dry deposition in a -semi-arid area, Atmos. Environ., 28, 2461-2471, 1994.

Leclerc, M. Y. and Thurtell, G. W., Footprint predictions of scalar fluxes using a Markovian analysis, Bound.-Lay. Meteorol., 52, 247-258, 1990.

Lewis, E. R. and Schwartz, S. E.: Sea salt aerosol production: mechanisms, methods, measurements, and models, Geophys. Monogr. Ser., 152, 413 pp., AGU, Washington, DC, 2004.

Mårtensson, M., Nilsson, E. D., de Leeuw, G., Cohen, L. H., and Hansson, H.-C.: Laboratory simulations of the primary marine aerosol generated by bubble bursting, J. Geophys. Res., 108, 4297, doi:10.1029/2002JD002263, 2003.

Mårtensson, M., Nilsson, E. D., Buzorius, G., and Johansson, C.: Eddy covariance measurement and parameterization of traffic related particle emissions in an urban environment, Atmos. Chem. Phys., 6, 769-785, 2006, http://www.atmos-chem-phys.net/6/769/2006/.

Nilsson, E. D., Rannik, U., Swietlicki, E., Leck, C., Aalto, P. P., Zhou, J., and Norman, M., Turbulent aerosol fluxes over the Arctic Ocean 2. Wind driven sources from the sea, J. Geophys. Res., 106, 32139-32154, 2001.

Nilsson, E. D., Mårtensson, E. M., Van Ekeren, J. S., de Leeuw, G., Moermann, M., and O'Dowd, C. D.: Primary marine aerosol emissions: size resolved eddy covariance measurements with estimates of the sea salt and organic carbon fractions, Atmos. Chem. Phys. Discuss., 7, 13345-13400, 2007, http://www.atmos-chem-phys-discuss.net/7/13345/2007/.

O’Dowd, C. D. and de Leeuw, G.: Marine aerosol production: a review of the current knowledge, Phil. Trans. R. Soc. A, 365, 1753-1774, 2007.

Pierce, J. R. and Adams, P. J.: Global evaluation of CCN formation by direct emission of sea salt and growth of ultrafine sea salt, J. Geophys. Res., 111, D06203, doi:10.1029/2005JD006186, 2006.

Pryor, S. C., Larsen, S. E., Sorensen, L. L., Barthelmie, R. J., Grönholm, T., Kulmala, M., Launiainen, S., Rannik, Ü., and Vesala, T., Particle fluxes over forests: Analyses of flux methods and functional dependencies, J. Geophys. Res., 112, D07205, 
doi:10.1029/2006JD008066, 2007.

Rannik, Ü. and Vesala T.: Autoregressive filtering versus linear detrending in estimation of fluxes by the eddy covariance method, Bound.-Lay. Meteorol., 91, 259-280, 1999.

Rosenfeld, D.: Suppression of rain and snow by urban and industrial air pollution, Science, 287, 1793-1796, 2000.

Sievering, H.: Profile measurements of particle mass transfer at the air-water interface, Atmos. Environ., 15, 123-129, 1981.

Slin, S. A. and Slin, W. G. N.: Predictions for particle deposition on natural waters, Atmos. Environ., 16, 301-306, 1980.

Slinn, W. G. N.: Predictions for particle deposition to vegetative canopies, Atmos. Environ., 16, 1785-1794, 1982.

Tjernstrom, M. and Friehe, C. A.: Analysis of a radome air-motion system on a twin-jet aircraft for boundary-layer research, J. Atmos. Ocean. Tech., 8, 19-40, 1991.

Tyree, C. A., Hellion, V. M., Alexandrova, O. A., and Allen, J. O.: Foam droplets generated from natural and artificial seawaters, J. Geophys. Res., 112, D11204, doi:10.1029/2006JD007729, 2007.
Vesala, T., Kljun, N., Rannik, Ü., Rinne, J., Sogachev, A., Markkanen, T., Sabelfeld, K., Foken, Th., and Leclerc, M. Y.: Flux and concentration footprint modeling: State of the art, Environ. Pollut., 152, 653-666, 2008.

Vesala, T., Järvi, L., Launiainen, S., Sogachev, A., Rannik, Ü., Mammarella, I., Siivola, E., Keronen, P., Rinne, J., Riikonen, A., and Nikinmaa, E.: Surface-atmosphere interactions over complex urban terrain in Helsinki, Finland, Tellus, 60B, 188-199, 2007.

US Census:http://www.census.gov, 2000.

Webb, E. K., Pearman, G. I., and Leuning, R.: Correction of flux measurements for density effects due to heat and vapor transfer, Q. J. Roy. Meteor. Soc., 106, 85-100, 1980. 